\title{
Association Between Work and Common Mental Disorders in School Adolescents: The ERICA Study
}

\author{
Daniele Baptista dos Santos iD,' Mauro Felippe Felix Mediano iD, I,II,* Luiz Fernando Rodrigues Júnior iD,' \\ Braulio dos Santos Junior iD,' Andrea Rocha de Lorenzo iD,' Maria Cristina Caetano Kuschnir iD ',III \\ 'Departamento de Pesquisa e Educacao, Instituto Nacional de Cardiologia, Ministerio da Saude, Rio de Janeiro, RJ, BR. "Instituto Nacional de Infectologia \\ Evandro Chagas, Fundacao Oswaldo Cruz, Rio de Janeiro, RJ, BR. "'I Faculdade de Medicina, Universidade Estacio de Sa, Rio de Janeiro, RJ, BR.
}

Santos DB, Mediano MFF, Rodrigues Júnior LF, Santos Júnior B, Lorenzo AR, Kuschnir MCC. Association Between Work and Common Mental Disorders in School Adolescents: The ERICA Study. Clinics. 2020;75:e1794

*Corresponding author. E-mail: mffmediano@gmail.com

OBJECTIVES: Adolescence is characterized by continuing profound mental, physical, and social changes and entering into the labor market during this phase may have negative consequences on physical and mental health. Common mental disorders (CMD) are characterized as disorders of mental functions, including symptoms of depression and anxiety as well as various nonspecific and somatic complaints such as reduced ability to concentrate, tiredness, irritation, and forgetfulness. Despite its increasing prevalence, few studies have addressed CMD and its association with work, in adolescents. In the present study, we aimed to identify the main factors associated with CMD and evaluated its association with work, in school adolescents.

METHODS: A cross-sectional study was conducted with 12 to 17 -year-old adolescent students using a selfadministered questionnaire with questions related to work. CMD was verified using the General Health Questionnaire of 12 items. In total, 3424 adolescents were studied.

RESULTS: The prevalence of CMD and work in the last year was $28.72 \%$ and $19.63 \%$, respectively. After adjustment for potential confounding variables, multivariate analysis showed associations of CMD with female gender $(\mathrm{OR}=2.72)$ and work $(\mathrm{OR}=1.70)$.

CONCLUSION: In the present study, a high number of cases of CMD were observed among the studied adolescents. Female gender and work history in the last year were negatively and independently associated with the presence of CMD.

KEYWORDS: Mental Health; Minor Labor; Adolescent Health; Blood Pressure.

\section{INTRODUCTION}

Adolescence is a phase of human development marked by continuing profound changes at the mental, physical, and social levels that requires adolescents to break from their past beliefs and move toward their personal and professional growth by making choices of life independently $(1,2)$. In some countries, adolescents can enter the job market; recent estimates indicate that about 3.4 million children and adolescents, between 10 and 17 years of age, work in Brazil. Brazilian law currently permits adolescents between 16 and 18 years of age to undertake labor activities with their social security rights guaranteed. The law also allows adolescents aged between 14 and 16 years to enter the job market as apprentices in technical and professional training programs. However, although labor by children and adolescents under

Copyright $\odot 2020$ CLINICS - This is an Open Access article distributed under the terms of the Creative Commons License (http://creativecommons.org/licenses/by/ 4.0/) which permits unrestricted use, distribution, and reproduction in any medium or format, provided the original work is properly cited.

No potential conflict of interest was reported.

Received for publication on February 21, 2020. Accepted for publication on June 17, 2020

DOI: 10.6061/clinics/2020/e1794
14 years old is prohibited by law in Brazil, it is still observed in some circumstances (3).

The entry of adolescents into the job market may be associated with a series of negative implications for their development, increasing their daily stress to a level that adolescents are not always psychologically prepared for and introducing adverse factors into their life by preventing them from performing the ludic and social activities common at their age. Moreover, the involvement of adolescents in the job market can have adverse consequences ranging from poor performance and dropping out of school to abnormalities in physical and mental health $(4,5)$. Other inherent risks for adolescent workers are work-related accidents during transportation to and from the workplace or resulting from a poor work environment (6).

Common mental disorders (CMD), also known as nonpsychotic disorders, are characterized by symptoms of depression and anxiety, besides various nonspecific and somatic complaints such as reduced ability to concentrate, tiredness, irritation, and forgetfulness (7). In recent decades, there has been an increase in its prevalence, not only in adults but also among adolescents, that is associated with numerous sociodemographic and environmental factors such as gender, income, education, smoking, and a sedentary lifestyle (8-10). 
Currently, there are a growing number of studies in the literature evaluating the relationship between mental health and work. This fact can be explained by the increased prevalence of mental and behavioral disorders in workers in several countries, including Brazil (11-13). However, studies on this topic, in adolescents, are still scarce, which is an important gap in the literature. Thus, in the present study, we aimed to identify the main factors associated with CMD and evaluate its association with work, in school adolescents.

\section{METHODS}

\section{Study Design}

The Study of Cardiovascular Risks in Adolescents (ERICA) was a national multicenter cross-sectional research project conducted with 12 to 17-year-old adolescent students enrolled in morning or afternoon shifts in public and private schools in municipalities with more than 100,000 inhabitants. The primary objective was to estimate the prevalence of cardiovascular risk factors and metabolic syndrome in adolescents (14). In addition, a database with relevant information was compiled during the ERICA study, on the quality of physical and mental health of school adolescents throughout Brazil. The details of the sample size calculation, criteria for selecting schools, and other instruments used, as well as the procedures on the day of data collection, can be found in other publications $(14,15)$.

In the present study, we used information from the ERICA study regarding the presence of CMD and work characteristics of the adolescents from schools located in the municipality of Rio de Janeiro. We included adolescents who did not present physical or mental disabilities that would preclude assessment of the investigated parameters and those who were not pregnant. The data were collected using a self-administered questionnaire comprising 103 questions divided into 11 blocks (sociodemographic aspects, occupational activities, physical activity, eating behavior, smoking, alcohol use, reproductive health, oral health, sleep duration, physical morbidity, and mental health) and were loaded on an electronic portable device. The application of the questionnaire was supervised by a school teacher or members of the study support team. The interviewee could contact any of them in case of questions.

All participating students signed the consent form and brought the free and informed consent form signed by their guardians. The study was approved by the Research Ethics Committee of the coordinating institution and each local center (IESC/UFRJ-Process 45/2008).

\section{Common Mental Disorder (Outcome)}

The CMD evaluation was performed using the Brazilian version of the General Health Questionnaire (16), consisting of 12 questions (GHQ-12), taking into account the last two weeks. The questions concerned the quality of sleep, the feeling of being nervous or tense, the ability to maintain attention, the feeling of being useful, the ability to face problems, the ability to make decisions, the ability to overcome difficulties, the feeling of being happy, the satisfaction of accomplishing daily tasks, the feeling of being sad or depressed, the feeling of being self-confident, and having self-esteem. Each question had four options: 1) not at all; 2) no more than usual; 3) a little more than usual; 4) much more than usual. The scores of the individual items were coded as absent (not at all and not more than usual) or present (a little more than usual and much more than usual), and students who scored three or more positive answers were classified as having CMD (17).

\section{Work (Exposure)}

The information related to work was collected through four questions: The first concerned paid work, the second concerned unpaid work, the third concerned the number of hours worked, and the last one concerned possible work accidents. All questions had an option in case the adolescent did not work. As the answers should take into account the experiences of the past year, the first and second questions (on paid and unpaid work) allowed the participant to mark more than one answer (company employee, household employee, intern, or freelancer). This study used data related to the form of work (paid or unpaid), number of hours worked, and possible work accidents.

\section{Covariates}

The clinical and sociodemographic covariates considered in this study were gender, age, pubertal development on the Tanner scale (18), self-reported skin color (white, black, mulatto, Asian, indigenous), type of school (public or private), school year ( $7^{\text {th }}$ to $9^{\text {th }}$ grade of elementary school and $1^{\text {st }}$ to $3^{\text {rd }}$ year of high school), study shift (morning or afternoon), parents' education (mother, father, and head of household), people with whom the adolescent resides (father, mother, both or none), and high blood pressure measured by the oscillometric method (systolic or diastolic blood pressure was above the $95^{\text {th }}$ percentile).

\section{Data Analysis}

The data analysis considered the complex sampling structure of the ERICA study, as it used stratification and conglomeration in its selection stages, and was performed using Stata 14.0 statistical software (Survey module). The descriptive statistics consisted of the mean (standard deviation) for continuous variables and the absolute frequency (percentage) for categorical variables.

The associations between the variables included in the study with the primary outcome (CMD) were investigated by univariate and multivariate logistic regression models with an estimate of the odds ratio (OR) and their respective confidence intervals of $95 \%(95 \% \mathrm{CI})$. In all analyses, a significance level of $5 \%$ was considered, maintaining all variables with $p<0.05$ in the multivariate model.

\section{RESULTS}

The main characteristics of the adolescents included in this study are shown in Table 1 . The sample consisted of 3424 adolescents with a mean age of 14.2 years; it showed a balanced distribution between genders (50.72\% male) and the participants were predominantly mixed-race $(46.77 \%)$. Most participants studied in public schools (72.67\%) and attended the morning shift $(89.89 \%)$, with $61.71 \%$ of the participants in the last three years of elementary school. Most were at puberty in the stage of sexual maturation (Tanner 2, 3, and 4: 61.12\%). Regarding the educational level of the parents or guardians, the most prevalent was tertiary education among fathers $(36.76 \%)$ and secondary education among mothers $(39.35 \%)$.

The prevalence of CMD among adolescents was $28.72 \%$. A minority of adolescents reported working at the time of the 
Table 1 - Characteristics of adolescents included in the study $(n=3424)$.

\begin{tabular}{|c|c|}
\hline VARIABLES & $\begin{array}{c}\text { FREQUENCY } \\
(\%)\end{array}$ \\
\hline \multicolumn{2}{|l|}{ Sex } \\
\hline Female & 49.28 \\
\hline Male & 50.72 \\
\hline \multicolumn{2}{|l|}{ Sexual maturation } \\
\hline Tanner Stage 1 & 0.29 \\
\hline Tanner Stage 2 & 4.43 \\
\hline Tanner Stage 3 & 18.51 \\
\hline Tanner Stage 4 & 38.18 \\
\hline Tanner Stage 5 & 38.59 \\
\hline \multicolumn{2}{|l|}{ Skin color $(n=3364)$} \\
\hline White & 39.46 \\
\hline Black & 11.22 \\
\hline Mixed-Race & 46.77 \\
\hline Asian & 2.07 \\
\hline Indigenous & 0.47 \\
\hline \multicolumn{2}{|l|}{ School administration } \\
\hline Public & 72.67 \\
\hline Private & 27.33 \\
\hline \multicolumn{2}{|l|}{ Educational level } \\
\hline Primary school $\left(7^{\text {th }}, 8^{\text {th }}\right.$, and $9^{\text {th }}$ grades $)$ & 61.71 \\
\hline Secondary school $\left(1^{\text {st }}, 2^{\text {nd }}\right.$, and $3^{\text {rd }}$ grades $)$ & 38.29 \\
\hline \multicolumn{2}{|l|}{ School shift } \\
\hline Morning & 89.89 \\
\hline Afternoon & 10.11 \\
\hline \multicolumn{2}{|l|}{ Father's educational level $(n=893)$} \\
\hline Illiterate & 1.55 \\
\hline Primary & 27.70 \\
\hline Secondary & 33.99 \\
\hline Tertiary & 36.76 \\
\hline \multicolumn{2}{|l|}{ Mother's educational level $(n=2500)$} \\
\hline Illiterate & 1.65 \\
\hline Primary & 26.40 \\
\hline Secondary & 39.35 \\
\hline Tertiary & 32.60 \\
\hline \multicolumn{2}{|l|}{ Householder's educational level $(n=2313)$} \\
\hline Illiterate & 2.00 \\
\hline Primary & 28.86 \\
\hline Secondary & 33.66 \\
\hline Tertiary & 35.48 \\
\hline \multicolumn{2}{|l|}{ Parents living with the adolescent } \\
\hline Mother & 36.22 \\
\hline Father & 4.88 \\
\hline Both parents & 54.06 \\
\hline No parents & 4.84 \\
\hline \multicolumn{2}{|l|}{ Paid work in the last year } \\
\hline No & 84.92 \\
\hline Yes & 15.08 \\
\hline \multicolumn{2}{|l|}{ Unpaid work in the last year } \\
\hline No & 88.22 \\
\hline Yes & 11.78 \\
\hline \multicolumn{2}{|l|}{ Paid or unpaid work in the last year } \\
\hline No & 80.37 \\
\hline Yes & 19.63 \\
\hline \multicolumn{2}{|l|}{ Current work hours per week $(n=3353)$} \\
\hline No current work & 90.22 \\
\hline$\leqslant 30$ hours & 9.36 \\
\hline$>30$ hours & 0.43 \\
\hline \multicolumn{2}{|c|}{ Work-related injury or illness in the last year $(n=3386)$} \\
\hline No & 21.51 \\
\hline Yes & 1.47 \\
\hline Blood pressure & \\
\hline Normal & 92.68 \\
\hline High & 7.32 \\
\hline Common mental disorder & \\
\hline No & 71.28 \\
\hline Yes & 28.72 \\
\hline
\end{tabular}

interview $(9.78 \%)$, and of these, only a small percentage $(0.43 \%)$ worked above the legal workload for this age group (>30 hours). The proportion of those who reported performing paid or unpaid work in the last year totaled $19.63 \%$, with a prevalence of work-related accidents or illnesses of $1.47 \%$ (Table 1). The percentage of CMD among adolescents who were in paid or unpaid work was $35.66 \%$, and was higher in those who reported having had a work-related accident or illness in the last year (55.37\%).

The associations between the variables included in the present study and the presence of CMD are shown in Tables 2 and 3 . In the univariate analysis, the CMD was associated with age (OR 1.13; 95\%CI 1.05-1.22), having an illiterate mother (OR 2.22; 95\%CI 1.40-3.50), residing only with their mother (OR 1.39; 1.13-1.71), being female (OR 2.60; 2.013.37), at Tanner stages 4 or 5 of sexual maturation (OR 1.62; 1.18-2.22), having worked in the past year (OR 1.50; 1.18 1.90), and having had a work-related accident or illness (OR $3.19 ; 1.40-7.26$ ). However, only female gender (OR 2.72; 95\% CI 2.10-3.52) and total work (OR 1.70; 95\%CI 1.32-2.18) remained associated with $\mathrm{CMD}$ in the multivariate analysis model.

\section{DISCUSSION}

The main finding of the present study was an important independent association between CMD with work and female gender in school adolescents. Other variables that were associated with the presence of CMD among adolescents in the univariate analysis were age, mother's education, residing only with mother, stage of sexual maturation, and the occurrence of any work accident in the last year, but these lost significance after adjustments for potential confounding variables.

The results of the present study are similar to those of a previous study conducted with 1211 participants aged over 15 years, which indicated a significant association between CMD, age, and female gender (19). The association between CMD and age may be justified by an increase in the prevalence of psychiatric disorders, chronic diseases, and exposure to stressful situations that are common with the advancement of age (20). Other researchers have also observed a higher prevalence of CMD among women, which may be associated with low education, poverty, domestic violence, and gender disadvantage $(21,22)$. Previous studies have also found an association between female gender and CMD among school adolescents (23).

The association between low maternal education and CMD described in the present study has also been observed by other researchers (24). In this context, the shorter the schooling time, the lower the socioeconomic level, with the latter being a risk factor observed for the development or maintenance of CMD (25). In addition, not living with parents has also been described as a possible social characteristic associated with CMD (23). However, in the present study, we found an association only among those adolescents who did not live with their mother, reinforcing the importance of the mother in the context of the adolescent's family (26).

The Tanner pubertal development stages 4 and 5, which represent adolescents in the final phase of sexual maturation and post-pubertal, respectively, were also associated with the 
Table 2 - Univariate associations between variables included in the study and common mental disorders.

\begin{tabular}{ll}
\hline VARIABLE & OR (95\% CI) \\
\hline Age (years) & $1.13(1.05$ to 1.22$)$ \\
Female sex & $2.60(2.01$ to 3.37$)$ \\
Non-white & $1.20(0.95$ to 1.51$)$ \\
Sexual maturation (Tanner 4 and 5) & $1.62(1.18$ to 2.22$)$ \\
Private school administration & 0.001 \\
Illiterate mother & $0.80(0.63$ to 1.03$)$ \\
Illiterate father & $2.22(1.40$ to 3.50$)$ \\
Illiterate householder & 0.13 \\
Living only with mother & $0.55(0.13$ to 2.34$)$ \\
Living only with father & $1.71(0.69$ to 4.30$)$ \\
Not living with parents (mother and father) & $1.39(1.13$ to 1.71$)$ \\
High blood pressure & 0.003 \\
Paid work in the last year & $0.91(0.55$ to 1.50$)$ \\
Unpaid work in the last year & $1.48(0.87$ to 2.52$)$ \\
Paid or unpaid work in the last year & $0.87(0.59$ to 1.28$)$ \\
Work-related injury or illness in the last year & $1.52(1.15$ to 1.99$)$ \\
\hline
\end{tabular}

Table 3 - Multivariate association between sex and work (paid or unpaid) in the last year with common mental disorders.

\begin{tabular}{lcc}
\hline VARIABLE & OR $(95 \% \mathrm{Cl})$ & p-value $^{1}$ \\
\hline Female sex & $2.72(2.10$ to 3.52$)$ & $<0.001$ \\
Paid or unpaid work in the last year & $1.70(1.32$ to 2.18$)$ & $<0.001$ \\
\hline
\end{tabular}

${ }^{1}$ Multivariate models were adjusted to those variables that were statistically significant in the univariate analysis (age, sex, sexual maturation (Tanner 4 and 5), illiterate mother, and living only with mother).

presence of CMD. Since Tanner's stages reflect human development, this association is probably related to the fact that the last two stages also represent older adolescents. In addition, the physical changes that occur during puberty may bring insecurity regarding acceptance from their peers, predisposing them to the occurrence of CMD (27).

In the present study, a significant association between CMD and work-related characteristics was observed, confirming the findings of other studies conducted in adult populations $(28,29)$. This association can be explained by the high level of psychological demand present in some types of work, dissatisfaction with remuneration, lack of physical or leisure activities, and low social support (30-32). In addition, a history of work-related accidents was also associated with CMD, as has been shown in other studies in adult populations (33). A study with 354 adolescent workers of various functions found a high report of body aches, a high incidence of accidents, and reduction in sleep duration on weekdays among those who worked, concluding that work activities in this age group should be directed to learning and not to laboring as an adult (34). As for work-related diseases, some have a direct connection with the work environment, such as situations of high demand, hard or dangerous occupations, low professional achievement, and responsibility for the lives of others. Moreover, depending on the meaning that the work has in the life of the subject, it will generate psychological distress, which can explain the relationship between illnesses and work-related accidents with CMD in adolescents (35).

In the multivariate analysis, only female gender and work remained associated with CMD. In the adult population, the association between work and mental health in women can be explained by the fact that the work environment is usually affected by social and cultural factors, with different work experiences between genders and a pronounced disadvantage for women due to their higher workload, since women in Brazil are primarily responsible for domestic work and family care (36). As a sample of adolescents were evaluated in this study, perhaps this result indicates that gender inequality; in particular, the work overload on women, is already present even before the social and cultural roles of men and women are defined. In this setting, multicomponent school-based interventions including innovative strategies (e.g. sports participation and positive development strategies) involving not only students but also school staff and parents may increase the psychosocial health, wellbeing, and quality of life of students and decrease school dropout rates $(37,38)$.

The main limitation of this study is that the data for CMD were collected using an instrument that verifies various symptoms without necessarily pointing to a diagnosis. However, the use of this type of instrument was necessary because data collection was performed at a single moment, and therefore it would not be possible to apply a battery of tests. However, the results are consistent with those found in the literature.

To conclude, in the present study, a high number of cases of CMD were observed among the studied adolescents. Female gender and work history in the previous year were independently associated with the presence of CMD. Thus, new research that further assesses the various factors associated with the presence of CMD among adolescents in the job market is critical for developing strategies for its prevention, identification, and treatment in this group.

\section{ACKNOWLEDGMENTS}

The ERICA study was funded by the Brazilian Ministry of Health (Science and Technology Department) and the Brazilian Ministry of Science and Technology (Financiadora de Estudos e Projetos/FINEP and Conselho Nacional de Pesquisa/CNPq) (grants FINEP: 01090421, CNPq: 565037/ 2010-2 and 405009/2012-7).

\section{AUTHOR CONTRIBUTIONS}

All authors included in this manuscript provided significant contributions to the work. Santos DB, Mediano MFF, Santos Junior B and Kuschnir MCC contributed to the study conception, design, analysis and interpretation of data. Santos DB, Mediano MFF, Rodrigues Junior LF, Santos Junior B, Lorenzo AR and Kuschnir MCG revised the manuscript critically for 
important intellectual content, and Santos DB, Mediano MFF, RodriguesJunior LF, Santos Junior B, Lorenzo AR and Kuschnir MCG approved the final version if the manuscript.

\section{REFERENCES}

1. Spear LP. The adolescent brain and age-related behavioral manifestations. Neurosci Biobehav Rev. 2000;24(4):417-63. https://doi.org/10.1016/ S0149-7634(00)00014-2

2. Sebastian C, Burnett S, Blakemore SJ. Development of the self-concept during adolescence. Trends Cogn Sci. 2008;12(11):441-6. https://doi.org/ 10.1016/j.tics.2008.07.008

3. Martins AC, Bassitt DP, Wanderley KS, Silva MS. Impact of urban child labor in the health of children and adolescents. Rev Bras Prom Saude. 2013;26(1):9-17. https://doi.org/10.5020/18061230.2013.p9

4. Hwang N, Domina T. The Links Between Youth Employment and Educational Attainment Across Racial Groups. J Res Adolesc. 2017;27(2): 312-27. https://doi.org/10.1111/jora.12277

5. Mortimer JT. The Benefits and Risks of Adolescent Employment. Prev Res. 2010;17(2):8-11.

6. Malta DC, do Prado RR, Caribe SS, da Silva MM, de Andreazzi MA, da Silva Júnior JB, et al. Factors associated with injuries in adolescents, from the National Adolescent School-based Health Survey (PeNSE 2012). Rev Bras Epidemiol. 2014;17 Suppl 1:183-202. https://doi.org/10.1590/ 1809-4503201400050015

7. Goldberg DP, Huxley P. Common mental disorders: a bio-social model. London: Routledge, 1992.

8. Steel Z, Marnane C, Iranpour C, Chey T, Jackson JW, Patel V, et al. The global prevalence of common mental disorders: a systematic review and meta-analysis 1980-2013. Int J Epidemiol. 2014;43(2):476-93. https://doi. org/10.1093/ije/dyu038

9. Lopes CS, Abreu Gde A, dos Santos DF, Menezes PR, de Carvalho KM, Cunha Cde F, et al. ERICA: prevalence of common mental disorders in Brazilian adolescents. Rev Saude Publica. 2016;50 Suppl 1(Suppl 1):14s. https://doi.org/10.1590/s01518-8787.2016050006690

10. Ludermir AB, Melo Filho DA. [Living conditions and occupational organization associated with common mental disorders]. Rev Saude Publica. 2002;36(2):213-21. https://doi.org/10.1590/S0034-891020020002 00014

11. Gritzka S, MacIntyre TE, Dorfel D, Baker-Blank JL, Calogiuri G. The Effects of Workplace Nature-Based Interventions on the Mental Health and Well-Being of Employees: A Systematic Review. Front Psychiatry. 2020;11:323. https://doi.org/10.3389/fpsyt.2020.00323

12. Nicholson PJ. Common mental disorders and work. Br Med Bull. 2018; 126(1):113-21. https://doi.org/10.1093/bmb/ldy014

13. Andrade LH, Wang YP, Andreoni S, Silveira CM, Alexandrino-Silva C, Siu ER, et al. Mental disorders in megacities: findings from the São Paulo megacity mental health survey, Brazil. PLoS One. 2012;7(2):e31879. https: / / doi.org/10.1371/journal.pone.0031879

14. Bloch KV, Szklo M, Kuschnir MC, Abreu Gde A, Barufaldi LA, Klein CH, et al. The Study of Cardiovascular Risk in Adolescents--ERICA: rationale, design and sample characteristics of a national survey examining cardiovascular risk factor profile in Brazilian adolescents. BMC Public Health 2015;15:94. https://doi.org/10.1186/s12889-015-1442-x

15. Vasconcellos MT, Silva PL, Szklo M, Kuschnir MC, Klein CH, Abreu Gde A, et al. Sampling design for the Study of Cardiovascular Risks in Adolescents (ERICA). Cad Saude Publica. 2015;31(5):921-30. https://doi.org/ 10.1590/0102-311X00043214

16. Mari JJ, Williams P. A comparison of the validity of two psychiatric screening questionnaires (GHQ-12 and SRQ-20) in Brazil, using Relative Operating Characteristic (ROC) analysis. Psychol Med. 1985;15(3):651-9. https://doi.org/10.1017/S0033291700031500

17. Goldberg DP, Williams P. A user's guide to the General Health Questionnaire. Windsor, Berks: Nfer-Nelson, 1988.

18. Tanner JM. Growth and maturation during adolescence. Nutr Rev. 1981; 39(2):43-55. https://doi.org/10.1111/j.1753-4887.1981.tb06734.x

19. Maragno L, Goldbaum M, Gianini RJ, Novaes HM, César CL. [Prevalence of common mental disorders in a population covered by the Family Health Program (QUALIS) in São Paulo, Brazil]. Cad Saude Publica. 2006;22(8):1639-48. https://doi.org/10.1590/S0102-311X2006000800012
20. Copeland WE, Shanahan L, Costello EJ, Angold A. Childhood and adolescent psychiatric disorders as predictors of young adult disorders. Arch Gen Psychiatry. 2009;66(7):764-72. https://doi.org/10.1001/archgen psychiatry.2009.85

21. Patel V, Kirkwood BR, Pednekar S, Pereira B, Barros P, Fernandes J, et al. Gender disadvantage and reproductive health risk factors for common mental disorders in women: a community survey in India. Arch Gen Psychiatry. 2006;63(4):404-13. https://doi.org/10.1001/archpsyc.63.4.404

22. Patel V, Kirkwood BR, Pednekar S, Weiss H, Mabey D. Risk factors for common mental disorders in women. Population-based longitudinal study. Br J Psychiatry. 2006;189:547-55. https://doi.org/10.1192/bjp.bp. 106.022558

23. Carvalho PD, Barros MVG, Santos CM, Melo EN, Oliveira NKR, Lima RA. The prevalence of and factors associated with negative mental health indicators in adolescents attending high school in the Brazilian State of Pernambuco. Rev Bras Saude Mater Infant. 2011;11(3):227-38. https:/ / doi. org/10.1590/S1519-38292011000300003

24. Fryers T, Melzer D, Jenkins R. Social inequalities and the common mental disorders: a systematic review of the evidence. Soc Psychiatry Psychiatr Epidemiol. 2003;38(5):229-37. https://doi.org/10.1007/s00127-003-0627-2

25. Marin-León L, Oliveira HB, Barros MB, Dalgalarrondo P, Botega NJ. Social inequality and common mental disorders. Braz J Psychiatry. 2007;29(3):250-3. https://doi.org/10.1590/S1516-44462006005000060

26. Brand AE, Klimes-Dougan B. Emotion socialization in adolescence: the roles of mothers and fathers. New Dir Child Adolesc Dev. 2010; 2010(128):85-100. https://doi.org/10.1002/cd.270

27. Oldehinkel AJ, Verhulst FC, Ormel J. Mental health problems during puberty: Tanner stage-related differences in specific symptoms. The TRAILS study. J Adolesc. 2011;34(1):73-85. https://doi.org/10.1016/j.adolescence. 2010.01.010

28. Braga LC, Carvalho LR, Binder MC. [Working conditions and common mental disorders among primary health care workers from Botucatu, São Paulo State]. Cien Saude Colet. 2010;15 Suppl 1:1585-96. https:/ /doi.org/ 10.1590/S1413-81232010000700070

29. Assunção AÁ, Machado CJ, Prais HA, de Araújo TM. Working conditions and common mental disorders in physicians in Brazil. Occup Med. 2013;63(3):234-7. https://doi.org/10.1093/occmed/kqt009

30. Souza MF, Silva Gde R. [Risk of minor psychiatric disorders in a metropolitan area of southeast Brazil]. Rev Saude Publica. 1998;32(1):50-8 https://doi.org/10.1590/S0034-89101998000100007

31. Souza SF, Carvalho FM, Araujo TM, Porto LA. Psychosocial factors of work and mental disorders in electricians. Rev Saude Publica. 2010; 44(4):710-7. https://doi.org/10.1590/S0034-89102010000400015

32. Stansfeld SA, Pike C, McManus S, Harris J, Bebbington P, Brugha T, et al. Occupations, work characteristics and common mental disorder. Psychol Med. 2013;43(5):961-73. https://doi.org/10.1017/S0033291712001821

33. Hilton MF, Whiteford HA. Associations between psychological distress, workplace accidents, workplace failures and workplace successes. Int Arch Occup Environ Health. 2010;83(8):923-33. https://doi.org/10.1007/ s00420-010-0555-x

34. Fischer FM, Oliveira DC, Nagai R, Teixeira LR, Lombardi Junior M, Latorre Mdo R, et al. [Job control, job demands, social support at work and health among adolescent workers]. Rev Saude Publica. 2005;39(2) 245-53. https: / /doi.org/10.1590/S0034-89102005000200016

35. Fischer FM, Oliveira DC, Teixeira LR, Teixeira MC, Amaral MA. Effects of work on the health of adolescents. Cienc Saude Colet. 2003;8(4):973-84. https://doi.org/10.1590/S1413-81232003000400019

36. Farias MD, Araujo TM. Common mental disorders among workers in the urban area of Feira de Santana - Bahia - Brazil. Rev Bras Saude Ocup. 2011;36(123):25-39. https://doi.org/10.1590/S0303-76572011000100004

37. Sancassiani F, Pintus E, Holte A, Paulus P, Moro MF, Cossu G, et al Enhancing the Emotional and Social Skills of the Youth to Promote their Wellbeing and Positive Development: A Systematic Review of Universal School-based Randomized Controlled Trials. Clin Pract Epidemiol Ment Health. 2015;11(Suppl 1 M2):21-40. https://doi.org/10.2174/17450179015 11010021

38. Sancassiani F, Lecca ME, Pintus E, Moro MF, Caria R, Minerba L, et al. Could an Innovative Training Program Including Contact Sports and Counseling Help Young People With Traits of Psychopathy and A History of School Dropout? Clin Pract Epidemiol Ment Health. 2019;15:49-57. https://doi.org/10.2174/1745017901915010049 